http://jmscr.igmpublication.org/home/ ISSN (e)-2347-176x ISSN (p) 2455-0450 crossref DOI: https://dx.doi.org/10.18535/jmscr/v8i1.154

\author{
Journal Of Medical Science And Clinical Research \\ IGM Publication \\ An Official Publication of IGM Publication
}

\title{
A Study on Histomorphological Patterns of Thyroid Lesions - An Experience of a Rural Tertiary Care Centre
}

\author{
Authors \\ K. Prathipa ${ }^{1 *}$, P.S. Vamitha ${ }^{2}$ \\ ${ }^{1}$ Assistant Professor, Department of Pathology, Chengalpattu Medical College, Tamil Nadu \\ ${ }^{2}$ Assistant Professor, Department of Pathology, Chengalpattu Medical College, Tamil Nadu \\ *Corresponding Author \\ Dr K.Prathipa
}

Assistant Professor, Department of Pathology, Chengalpattu Medical College, Tamil Nadu, India

\begin{abstract}
Objective: Thyroid lesions are the most common endocrine problem encountered in routine clinical practice. This study describes the various spectrums of thyroid lesions in surgically resected specimen and its correlation with age, gender and cytological findings.

Materials and Methods: A retrospective study of thyroid lesions were conducted in the Department of pathology in a rural tertiary care centre over a period of 1 year from Jan 2018 to Dec 2018. Totally 145 cases were studied which include 109 non neoplastic, 7 benign and 29 malignant cases. Histopathological findings and its correlation with various parameters were evaluated.

Results: Totally 145 surgically resected thyroid specimens were received during the study period of one year with a female: male ratio of 10.7: 1. The age group ranges from 14 years to 67 years and peak incidence was noted in 31-40 years group. Most common lesion noted was nodular goiter (54\%) followed by thyroid malignancies (20\%). Other lesions observed were thyroiditis (14\%), follicular adenoma (5\%), nodular hyperplasia with thyroiditis (6\%) and toxic goiter (1\%). Among the malignant tumours, the predominant lesion was papillary carcinoma (90\%) followed by follicular (7\%) and medullary carcinoma (3\%).

Conclusion: Non neoplastic lesions are more common than neoplastic lesions with a striking female predominance. This study shows increased prevalence of thyroid lesions with a rising incidence of papillary carcinoma thyroid among the middle aged individuals especially males.

Keywords: thyroid lesions, FNAC, papillary carcinoma, goitre.
\end{abstract}

\section{Introduction}

Thyroid lesions are one of the most common endocrine problem second to diabetes ${ }^{[1]}$ with greater part of them are benign in nature ${ }^{[2]}$. They are endemic in mountainous regions of the world having little iodine supply in soil and water. The prevalence and pattern of thyroid disorders depend on various factors including sex, age, ethnic and geographical patterns. ${ }^{[3]}$ Most of the thyroid lesions are benign nodule and only $5 \%$ are considered to be malignant. ${ }^{[4]}$ Thyroid malignancies represent $1.5 \%$ of all cancer but it is the commonest endocrine cancer accounting for $92 \%$ of all endocrine malignancies. ${ }^{[5]}$

\section{Materials and Method}

A retrospective descriptive study of thyroid lesions was conducted in the Department of pathology in a 
rural tertiary care centre over a period of 1 year from Jan 2018 to Dec 2018. All the biopsy reports were retrieved and various clinical parameters include age, gender, thyroid profiles and relevant investigations like FNAC\& radiological reports were evaluated. All the biopsies were fixed in $10 \%$ buffered formalin and routinely processed for paraffin embedding and sections were stained with Haematoxylin and Eosin.

\section{Results:}

A total of 145 surgically resected thyroid specimens were received during the one year study period. Resected specimens ranged from hemithyroidectomy to total thyroidectomy. The common presenting symptom is thyroid enlargement includes multinodular goiter (61\%) followed by solitary nodule $(28 \%)$ and diffuse symmetrical enlargement (11\%). Age incidence ranged from 14-67 years with a mean age of 38 years and peak age incidence noted in the age group $31-40$ years $(34 \%)$ followed by $41-50$ years $(25 \%)$ [Chart 1] Only $6 \%$ of cases were observed in age group below 20 years.

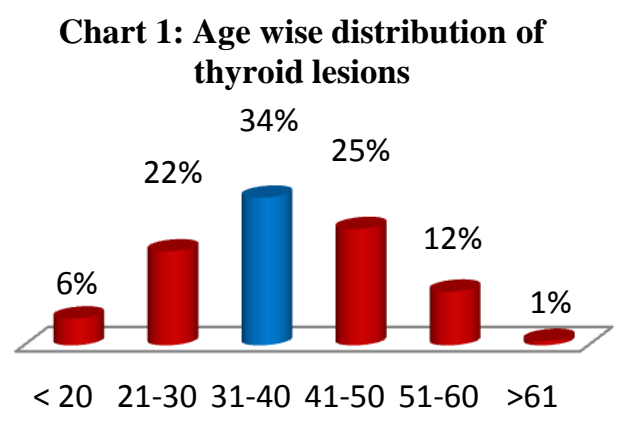

Sex predilection was seen for females $(91 \%)$ with a female: male ratio was 10.1:1 [Chart 2].

Chart 2: Sex wise distribution of thyroid lesions

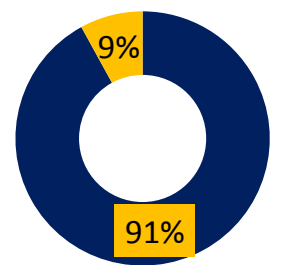

- FEMALE MALE
Of the total 145 cases non neoplastic lesion constitutes $75 \%$ followed by malignant lesion (20\%) and benign 5\%. [Chart 3]

\section{Chart 3: Histopathological categorization}

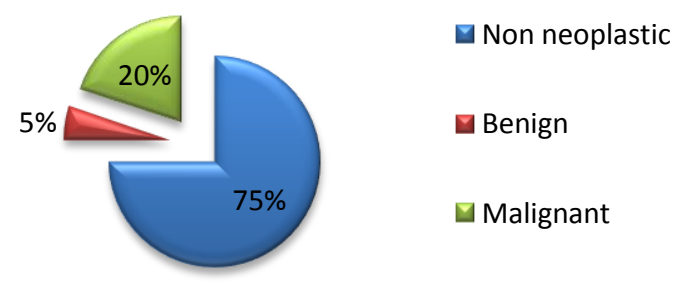

\begin{tabular}{|lcc|}
\hline $\begin{array}{l}\text { Table 1: Sex wise distribution } \\
\text { Carcinomas }\end{array}$ & Thyroid \\
\hline $\begin{array}{l}\text { Sex } \\
\text { No of malignancy/total no } \\
\text { of cases }\end{array}$ & $\%$ \\
\hline Male & $5 / 13$ & $38 \%$ \\
\hline Female & $24 / 132$ & $18 \%$ \\
\hline
\end{tabular}

Most common non neoplastic lesion was nodular goiter $(54 \%)$ followed by thyroiditis (14\%). common lesion noted was nodular goiter $(54 \%)$ followed by thyroid malignancies $(20 \%)$. Other lesions observed were follicular adenoma (5\%), nodular hyperplasia with thyroiditis $(6 \%)$ and toxic goiter (1\%) [Table 2]. Carcinoma accounts for 29 cases $(20 \%)$ with highest incidence seen in the age group 31-40 years followed closely by 41-50 years.

\begin{tabular}{|lcc|}
\hline $\begin{array}{l}\text { Table 2: Histopathological } \\
\text { thyroid lesions }\end{array}$ & No of cases & $\mathbf{\%}$ \\
\hline Diagnosis & 78 & $54 \%$ \\
\hline Nodular goiter & 21 & $14 \%$ \\
\hline Hashimoto thyroiditis & 8 & $6 \%$ \\
\hline $\begin{array}{l}\text { Nodular hyperplasia } \\
\text { thyroiditis }\end{array}$ & 2 & $1 \%$ \\
\hline Toxic goitre & 7 & $5 \%$ \\
\hline Follicular adenoma & 29 & $20 \%$ \\
\hline Malignant lesion & & \\
\hline
\end{tabular}

Male patients in the age group of 31-40 years were most commonly affected by malignant lesion followed by 41-50 years [Chart 4]. 
Chart 4: Age wise distribution of thyroid carcinoma

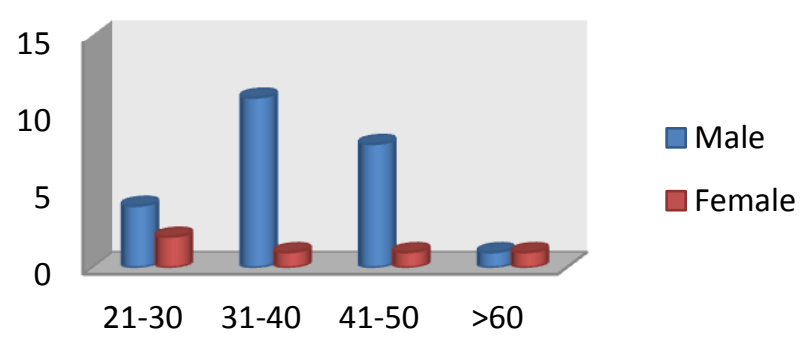

Out of the 29 malignant tumours, the predominant lesion was papillary carcinoma (90\%) followed by follicular (7\%) and medullary carcinoma (3\%). Most common histopathological type of papillary carcinoma observed was conventional type (55\%) followed by conventional type with associated Hashimoto thyroiditis.

\begin{tabular}{|lcc|}
\hline $\begin{array}{l}\text { Table 3: Histopathological types of Papillary } \\
\text { carcinoma }\end{array}$ & No of cases & $\%$ \\
\hline Type & 14 & $55 \%$ \\
\hline Conventional type & 5 & $19 \%$ \\
\hline $\begin{array}{l}\text { Conventional associated } \\
\text { with Hashimoto thyroiditis }\end{array}$ & 4 & $14 \%$ \\
\hline Follicular variant & 1 & $4 \%$ \\
\hline Macrofollicular variant & 1 & $4 \%$ \\
\hline Oncocytic ariant & 1 & $4 \%$ \\
\hline Microcarcinoma variant & & \\
\hline
\end{tabular}

Among the variants follicular type constitutes (14\%) followed by microcarcinoma, macrofollicular variant and oncocytic variant (4\% each) [Table 3]. About 5 cases were associated with Hashimotos thyroiditis (19\%).

\section{Discussion}

Thyroid lesions are the most common endocrine disease encountered worldwide. Majority of the patients are from developing countries due to the increased prevalence of iodine deficiency. Clinical presentation of thyroid disease may be in the form of multinodular, solitary or diffuse enlargement. ${ }^{[6]}$ In this study, the peak incidence of thyroid lesions are seen in the age group 31-40 years (34\%) with mean age of presentation was 38 years in concordance with studies conducted by Joseph et al. ${ }^{[7]}$ The overall distribution thyroid lesions in this study were $75 \%$ non neoplastic, $5 \%$ benign and $20 \%$ malignant similar to studies conducted by Hussain et $\mathrm{al}^{[8]}$, Joseph et $\mathrm{al}^{[7]}$ and Rahman et $\mathrm{al}^{[9]}$. Compared to other studies, the present study showed higher female predilection with female: male ratio noted was 10.1:1. Female: male ratio noted in previous studies were 3.4:1 Chukudebelu et $\mathrm{al}^{[10]}, 4.5: 1$ Tsegaye et $\mathrm{al}^{[11]}$. Various reports from the United States of America, Saudi Arabia and Pakistan, which recorded female to male ratios of $7: 1,6.2: 1$ and $4.5: 1$, respectively. ${ }^{[12],[13],[14]}$. The commonest non neoplastic lesion observed in this study was simple nodular goiter $(54 \%)$ similar to studies by Tsegaye et al ${ }^{[11]}$, Ijomone et al in Nigeria reported 59.4\% ${ }^{[15]}$, Misiakos et al in Greece $(54.9 \%)^{[16]}$, Joseph et al $(71.5 \%)^{[7]}$. Among the non neoplastic lesions, the second commonest pathology observed was thyroiditis (14\%) in concordance with studies by Joseph et al $(22.97 \%)^{7}$ and Sherine I Salama et al $(7.6 \%)^{[17]}$. Other studies reported low incidence of thyroiditis were Rahman et al in Bangaladesh $(2.7 \%)^{[9]}$, Raphael solomon et al in Nigeria $(0.4 \%)^{[18]}$, Misiakos et al in Greece $(3.8 \%)^{[16]}$. Thyroiditis was noted as an associated finding in $6 \%$ of nodular goiter compared to a study by Joseph et $\mathrm{al}^{[7]}$ showed $17.6 \%$ of multinodular goiters.

In this study neoplastic lesions constituted $25 \%$, within the neoplastic lesions malignancy (20\%) predominates over benign adenomas (5\%) concordant with studies by Abdulkader Albasri et al [19] and Joseph et $\mathrm{al}^{[7]}$. This study showed low incidence of benign follicular adenoma (5\%) similar to studies Abdulkader Albasri et al $(8.6 \%)^{[19]}$ and Joseph et al $(3.3 \%)^{[7]}$ and discordant to studies by Ijomone EA et al $(52.4 \%)^{[15]}$, Raphael solomon et al in Nigeria $(52.2 \%)^{[17]}$. Thyroid adenoma $(5 \%)$ was the only benign lesion observed in this study. Papillary carcinoma was the most common malignant lesion accounting $90 \%$ of malignant lesions and $17.9 \%$ of all thyroid lesions which is similar to findings by Abdulkader Albasri et al ${ }^{[19]}$, Chukudebelu et $\mathrm{al}^{[10]}$, Ariyibi et $\mathrm{al}^{[20]}$ and Ashwini $\mathrm{K}$ et $\mathrm{al}^{[21]}$. In contrast to most other studies, Olurin et $\mathrm{al}^{[22]}$, cameroun and omran et $\mathrm{al}^{[23]}$ found that follicular carcinoma was the commonest malignant 
neoplasm. The probable explanation was wide prevalence of iodine deficiency or partly by the miss interpretation of the follicular variant of papillary carcinoma as follicular carcinoma in earlier classification of thyroid neoplasms. The peak age incidence of papillary carcinoma was $3^{\text {rd }}$ and $4^{\text {th }}$ decade similar to studies by Ariyibi et al ${ }^{[20]}$, Joseph et $\mathrm{al}^{[7]}$ and in contrast to study by Abdullah $\mathrm{H}$. Darwish et $\mathrm{al}^{[24]}$, he observed most of the papillary carcinoma were diagnosed more than 60 years. Most recent studies have reported incidence of thyroid malignancy in Hashimoto thyroiditis was $29.4 \%{ }^{[25]}$. We observed coexistent papillary carcinoma and Hashimoto thyroiditis in 5 cases (19\%). Follicular variant (14\%) was the most common variant observed among the papillary carcinoma and one case in each variant includes microcarcinoma, macrofollicular and oncocytic variant consistent with study by Sherine I Salama et al ${ }^{[18]}$. Incidence of other malignancies observed were 2 cases of follicular carcinoma and 1 case of medullary carcinoma. In this study cytological correlation was performed in 52 cases. About $78.8 \%$ of cases correlated and $21.1 \%$ not correlated with histopathology. In our study, 9 patients with false negative and 2 cases with false positive diagnoses were reported among malignant cases. The overall incidence of malignancy was increased from $15 \%$ to $25 \%$ after thyroidectomy.

\section{Conclusion}

In our study nodular goiter was the most common histopathological lesion followed by thyroiditis. Malignant neoplasms were more common than benign neoplasms. Papillary carcinoma was the most common malignant neoplasm. This study show increased prevalence of thyroid lesions with a rising incidence of papillary carcinoma thyroid among the middle aged male individuals. Improved imaging techniques and correct FNA diagnoses may facilitate early diagnosis of malignant thyroid lesion.

\section{References}

1. Kochupillai N. Clinical endocrinology in India. CurrSci. 2000; 79:1061-7.
2. Burguera B, Gharib H. Thyroid incidentalomas. Prevalence, diagnosis, significance and management. Endocrinol Metab Clin North Am 2000;29:187-203.

3. Bayliss R. Thyroid disease. The fact, Oxford University press. New York. Toronto. 1982.

4. AACE/AME Task force on Thyroid Nodules. American Association of Clinical Endocrinologists. Guidelines for clinical practice for the diagnosis and management of thyroid nodule. Endocr Pract. 2006; 12:63-102.

5. Niazi S, Arshad M, Muneer M. A histopathological audit of thyroid surgical specimens. Annals King Edward Med Coll 2007;13:51-6.

6. Galofre JC, Lomvardlias S, Davies TF. Evaluation and treatment of Thyroid nodules: a clinical guide. Mt Sinai J Med 2008;75:299-311.

7. Elizabeth Joseph et al. A study on the histopathological pattern of thyroid lesions in a tertiary care hospital. Int J Res Med Sci.2016 Dec; 4(12): 5252-5255.

8. Hussain N, Anwar. M, Nadia N, Ali Z. Pattern of surgically treated thyroid diseases in Karachi. Biomedical 2005; 21:18-20.

9. Rahman MA, Biswas MA, Siddika ST et al. Histomorphological pattern of thyroid lesions. Dinajpur Med Col J (2016);6:13440.

10. Chukudebelu O, Dias A, Timon C. Changing trends in thyroidectomy. Ir Med J.2012;105:167-9

11. Tsegaye B, Ergete W. Histopathological pattern of thyroid diseases. East Afr Med J.2003; 80:525-8.

12. Chung EB, Rogers N, White JE. Thyroid diseases in Black patients. J Natl Med Assoc 1977;69:5737

13. AbuEshy SA, AlShehry MY, Khan AR, Khan GM, AlHumaidi MA, Malatani TS. Causes of Goiter in the Asir region: A histopathological analysis of 361 cases. Ann Saudi Med 1995;15:746 
14. Hussain N, Anwar M, Nadia N, Ali Z. Pattern of surgically treated thyroid diseases in Karachi. Biomedica 2005; 21:1820

15. Ijomone EA et al. Histopathological review of thyroid dieases in southern Nigeria- a ten year retrospective study. J of Med and Medl Sci 2014; 5(6): 127-132.

16. Misiakos EP, Liakakos T, Macheras A et al. Total thyroidectomy for the treatment of thyroid diseases in an endemic area. South Med J 2006; 99: 1224-9.

17. Sherine I Salama et al. Histopathological pattern of thyroid lesions in Western region of Saudi Arabia. The New Egyptian J of Med 2009; 40(6); 580-585.

18. Raphael Solomon, Yawale Iliyasu, AZ Mohammed. Histopathological pattern of thyroid lesions in Kano, Nigeria: A 10year retrospective review (2002-2011). Niger J Basic Clin Sci 2015;12:5560

19. Abdulkader Albasri, zeinab Sawaf, Akbar Shah Hussainy. Histopathological patterns of thyroid disease in Al-Madinah region of Saudi Arabia. Asian Pac J cancer Prev 2014;15(14): 5565-5570.

20. Ariyibi OO, Duduyemi BM, Akang EE,Oluwasola Ao. Histopathological pattern of thyroid neoplasms in Ibadan, Nigeria: A twenty year retrospective study. Int $\mathbf{J}$ of tropical disease \& Health 2013; 3: 148-56.

21. Ashwini K, Anitha B, Letha P. Pattern of thyroid disorder in thyroidectomy specimen. Inter J Med Scie Pub Health. 2014;3:1446-8.

22. Olurin EO, Itayemi SO, OLuwasanmi JO. The pattern of thyroid gland disease in Ibadan. Nigeria Med J. 1973; 3(2):60-61.

23. Omran M, Ahmed ME. Carcinoma of thyroid in Khartoum. East Afr Med J. 1993;70(3): 159-162.

24. Abdullah H Darwish, Khalid A. Al Sindi, Jihene El Kafsi. Pattern of Thyroid diseases - A Histopathological Study. Bahrain Med Bull 2006; 28(4): 1-6.
25. Zhang Y, Dai J, wu T, Yang N, Yin Z. The study of the coexistence of Hashimoto's thyroiditis with papillary thyroid carcinoma. J Cancer Res Clin Oncol. 2014;140:1021-6. 